\title{
Diversidade nas organizações: uma análise das produções científicas nos eventos da ANPAD
}

Percebe-se atualmente que a diversidade está cada vez mais presente dentro das organizações, sendo assim este trabalho teve como objetivo analisar as produçõe científicas sobre a temática da diversidade LGBTQ+ dentro das organizações nos principais eventos da Associação Nacional dos Programas de Pós-graduação em Administração (ANPAD) nos últimos 15 anos. No que se refere aos procedimentos metodológicos adotados no presente trabalho, este estudo caracteriza-se como uma pesquisa bibliométrica. Para tanto, realizou-se um levantamento de artigos científicos sobre a temática, publicados entre os anos de 2006 a julho de 2020 nos principais eventos da ANPAD. Em um primeiro momento, foram selecionados os artigos que possuíam no título a palavra 'gay', 'lésbica', 'homossexual' e 'Igbt'. No segundo estágio, os trabalhos localizados foram lidos, a fim de verificar se realmente tratavam sobre a temática da diversidade sexual e de gênero nas organizações. Com base nos resultados do presente estudo, foi possível averiguar que as pesquisas realizadas trazem importantes contribuições para o meio científico e acadêmico acerca da temática da diversidade sexual e de gênero nas organizações. Verifica-se um crescimento de publicações dentro da plataforma da Associação Nacional de Pós-graduação e Pesquisa em Administração (ANPAD) sobre a temática, o que demonstra o interesse por parte dos pesquisadores em compreender melhor de que forma a inclusão está acontecendo dentro das empresas.

Palavras-chave: Diversidade; Organizações; LGBT

\section{Diversity in organizations: an analysis of scientific production at ANPAD events}

\begin{abstract}
It is now perceived that diversity is increasingly present within organizations, so this work aimed to analyze scientific productions on the theme of LGBTQ + diversity within organizations in the main events of the National Association of Graduate Programs in Administration (ANPAD) in the last 15 years. With regard to the methodological procedures adopted in the present work, this study is characterized as a bibliometric research. To this end, a survey of scientific articles on the subject was carried out, published between the years 2006 and July 2020 in the main events of ANPAD. At first, articles that had the word 'gay', 'lesbian', 'homosexual' and 'Igbt' were selected in the title. In the second stage, the localized works were read, in order to verify if they really dealt with the theme of sexual and gender diversity in organizations. Based on the results of the present study, it was possible to ascertain that the research carried out brings important contributions to the scientific and academic environment on the theme of sexual and gender diversity in organizations. There is a growth in publications within the platform of the National Association of Graduate Studies and Research in Administration (ANPAD) on the subject, which demonstrates the interest on the part of researchers to better understand how inclusion is happening within companies.
\end{abstract}

Keywords: Diversity; Organizations; LGBT.

Topic: Recursos Humanos

Reviewed anonymously in the process of blind peer
Received: 09/01/2021

Approved: 21/03/2021
Matheus Machado Laurini

Faculdade Integrada de Santa Maria, Brasil http://lattes.cnpq.br/2634472466639035 http://orcid.org/0000-0003-2819-4532 mmlaurini@ucs.br

Andressa Schaurich dos Santos

Faculdade Integrada de Santa Maria, Brasi http://lattes.cnpq.br/2247093929888265 http://orcid.org/0000-0002-5332-8486 andressa.santos@fisma.com.br
Referencing this:

LAURINI, M. M.; SANTOS, A. S.. Diversidade nas organizações: uma análise das produções científicas nos eventos da ANPAD. Revista Brasileira de Administração Científica, v.12, n.1, p.83-93, 2021. DOI: http://doi.org/10.6008/CBPC2179-684X.2021.001.0007 


\section{INTRODUÇÃO}

Com a ascensão da globalização e o uso da tecnologia a diversidade das relações humanas tem sido cada vez mais discutida no mundo moderno, inclusive nas organizações, uma vez que o perfil dos trabalhadores passou a ser o mais amplo possível. Essa pluralidade, de acordo com Freitas et al. (2012), se deu a partir da Segunda Guerra Mundial, quando as mulheres começaram a se inserir no mercado de trabalho. Além disso, a globalização fez com que diferentes culturas convivessem no mesmo espaço organizacional. Dentro desse contexto da diversidade nas empresas, está inserido o público LGBTQ+ (Lésbicas, gays, bissexuais, travestis, transexuais e queer).

Segundo um levantamento feito por Debeluck et al. (2015), a estimativa é que exista um contingente expressivo de indivíduos que façam parte do grupo LGBTQ+ no Brasil, número esse que gira em torno de $9 \%$ da população (cerca de 18 milhões de pessoas), sendo que destes $25,5 \%$ são gays, $23,4 \%$ bissexuais e 7,6\% lésbicas. Partindo para o campo organizacional, em uma pesquisa aplicada pela empresa de consultoria em Gestão de Pessoas Elancers, citada por Sales (2017), verificou-se que aproximadamente 7\% das organizações brasileiras não contratariam pessoas homossexuais de forma alguma e outras $11 \%$ jamais os escolheriam para representá-las.

Outra recente pesquisa, realizada pelo Trades Union Congress (2017), mostra que 1 a cada 3 pessoas LGBTQ+ relatou ter passado por algum tipo de preconceito no mercado de trabalho no Reino Unido. Na mesma pesquisa também foi possível verificar que $62 \%$ dos entrevistados já sofreram alguma piada ou agressão por parte de seus colegas laborais.

Na visão de Donelly (2003) não é difícil verificar que as minorias sexuais e de gênero são alvo de discriminação e preconceito em decorrência de seu modo de ser e existir na sociedade. Segundo o autor, as minorias sexuais e de gênero englobam sujeitos menosprezados no meio em que estão inseridos, única e exclusivamente em decorrência de sua orientação sexual ou identidade de gênero, que vão na contramão do padrão heteronormativo, que cultural e historicamente é branco, masculino, de tipo físico magro, católico, entre outras características. Nogueira et al. (2015) complementa que a heteronormatividade é uma idealização da expressão de gênero, é a imposição social de que todos se comportem como heterossexuais, mesmo que não tenham práticas heterossexuais. Partindo desse princípio, compreende-se que o homem deve ser masculino e forte e a mulher deve ser feminina e frágil.

Diante deste cenário e a frente do seu tempo, após os fortes horrores ocasionados pela Segunda Guerra Mundial, no ano de 1948 a ONU (Organização das Nações Unidas) acolheu a Declaração Universal dos Direitos Humanos, a fim de proporcionar uma vida justa e livre para todos os indivíduos. Ainda neste sentido, compreende-se que os direitos humanos devem atingir a todos os seres humanos, independente de raça, sexo, nacionalidade, etnia, religião ou qualquer outra condição (ONU, 1948). Contudo, desde o ano de 1990 a ONU registra diversos tipos de violações dos direitos à diversidade sexual, o que confirma a teoria de Donelly (2003) de que as minorias sexuais são vítimas de preconceito e discriminação na sociedade em que estão inseridas e justifica a construção de políticas que visem fomentar a igualdade de direitos à gays, 
lésbicas, bissexuais, travestis e transexuais.

Diante dos pontos expostos e de acordo com os autores Yilmaz et al. (2016), é perceptível que a entrada e permanência no mercado de trabalho é de difícil acesso para os que são considerados minoria, como se houvesse uma separação do que é aceitável ou não dentro dos ambientes organizacionais. Partindo deste princípio, tem-se como objetivo geral deste estudo analisar as produções científicas sobre a temática da diversidade LGBTQ+ dentro das organizações nos principais eventos da Associação Nacional dos Programas de Pós-graduação em Administração (ANPAD) nos últimos 15 anos. Para tanto, levou-se como referência as pesquisas publicadas entre os anos de 2006 a julho de 2020 nos seguintes eventos: Encontro da Associação Nacional dos Programas de Pós-graduação em Administração (EnANPAD), Encontro de Gestão de Pessoas e Relações de Trabalho (EnGPR) e Encontro de Estudos Organizacionais (EnEO).

O tema proposto justifica-se pela sua perceptível relevância no atual contexto político e social do país, além de aprofundar seus estudos no meio científico. Segundo Freitas Junior (2006) o trabalho é visto como uma forma de realização do ser humano como pessoa na sociedade, assim sendo, estar excluído do mercado de trabalho, significa estar excluído da sociedade. Portanto, de acordo com Biscalchim et al. (2016), é necessário então buscar reflexões acerca das problemáticas enfrentadas por pessoas LGBTQ+ no mercado de trabalho, tornando-se ainda imprescindível dar luz sobre as relações existentes dentro do ambiente de trabalho e refletir sobre a complexidade envolta nos processos de construção da identidade de um segmento da população cada vez mais expressivo e heterogêneo. Assim, espera-se que este estudo contribua cientificamente para a compreensão da pluralidade humana e para a promoção da diversidade sexual e de gênero nas organizações.

\section{REVISÃO TEÓRICA}

\section{A diversidade sexual e de gênero na sociedade}

De acordo com o Instituto Ethos (2013), existem diversas variáveis pelas quais a pluralidade humana, mais especificamente a diversidade sexual e de gênero, são ignoradas na sociedade e somente um único padrão é considerado normal. Esse padrão é heterossexual, masculino, de biótipo magro, católico, entre outras características (DONELLY, 2003; SOARES et al., 2018). Ainda conforme o Instituto Ethos (2013), com base nesse padrão são idealizados estereótipos e todas as pessoas que não se enquadram nesses estereótipos pré-estabelecidos são vítimas de discriminação e preconceito pelos membros da sociedade da qual fazem parte.

Ao padrão heterossexual citado acima, damos o nome de heteronormatividade, que pode ser entendido como um sistema ideológico que nega, difama e recrimina qualquer forma não heterossexual de comportamento, identidade e relacionamento (HEREK, 1992). Esse sistema gera privilégios para pessoas que praticam as normas heterossexuais e exclui aquelas que não as praticam. "Esses privilégios incluem direitos civis para casamentos entre heterossexuais, tratamento social não estigmatizado em razão de sua sexualidade, entre outros" (SOUZA et al., 2013). 
De acordo com Donelly (2003), as minorias sexuais são vítimas de discriminação e preconceito na sociedade em que estão inseridas, única e exclusivamente em decorrência de sua orientação sexual. Essas discriminações e preconceitos voltados aos homossexuais tornou-se conhecida como homofobia, que é percebida como aversão e em alguns casos até ódio por pessoas homossexuais. Esses preconceitos são sentidos na pele por crianças, adolescentes, jovens e adultos, sejam eles sofridos em casa, pela não aceitação por parte da família e amigos, na escola e até mesmo no mercado de trabalho (SOUSA, 2016; JUNQUEIRA, 2007; PRADO et al., 2008).

Até poucos anos atrás as legislações ignoravam a presença de pessoas LGBTQ+ na sociedade e a justiça, por diversas vezes, negou aos homossexuais o direito à adoção e o direito ao reconhecimento legal de suas uniões. A Constituição de 1988, ao instituir o Estado Democrático de direito, assegurou a todos os indivíduos à igualdade, à liberdade e o bem-estar e sendo assim, entre outros direitos, garantiu uma sociedade livre de preconceitos e discriminações (CARRARA et al., 2006; SOUSA, 2016).

Então, mesmo nas diferenças, deve o Estado promover a saúde, a educação, o trabalho, a livre orientação sexual, bem como resguardar os direitos inerentes a homoafetividade. Não podendo sob nenhum pretexto obliterar o pleno exercício da sexualidade individual. Afinal a cidadania deve alcançar a todos, indistintamente, independente de raça, cor, sexo ou religião, acrescente-se, orientação sexual. (SOUSA, 2016)

Contudo, já se passaram mais de três décadas desde a promulgação da Constituição de 1988 e ainda nos deparamos com as mais variadas situações que muitas vezes negam e excluem os direitos fundamentais das minorias sexuais e de gênero (SOUSA, 2016).

Mesmo diante dos pontos expostos até aqui, é impossível negar que no decorrer dos últimos anos importantes avanços foram conquistados pelas pessoas LGBTQ+. Pode-se apontar as ações mais relevantes do Governo Federal, como o Programa Brasil sem Homofobia (2004); Plano Nacional de Cidadania e Direitos Humanos LGBT (2009); Conselho Nacional de Combate à discriminação LGBT (2010); e o Sistema Nacional de Promoção de Direitos e Enfrentamento à Violência Contra LGBT (2013) (CARRARA et al., 2006; MELLO et al., 2012; ARAGUSUKU et al., 2014).

No âmbito judiciário, no ano de 2011 uma importante vitória foi conquistada, pois o Supremo Tribunal de Justiça reconheceu como legítima a união estável entre pessoas do mesmo sexo e mais tarde, em 2013, por meio do Conselho Nacional de Justiça, foi publicada a Resolução № 175, de 14 de maio de 2013, que proíbe a recusa de celebração pelos cartórios de casamento civil ou conversão em união estável entre pessoas do mesmo sexo (MELLO et al., 2012). De acordo com Aragusuku et al. (2014), tais políticas, desenvolvidas e fomentadas nos últimos anos representam grandes avanços na possibilidade de transformação na vida de pessoas LGBTQ+.

Nas últimas décadas, o movimento LGBTQ+ constitui-se como um importante representante político coletivo na sociedade, fazendo com que temas polêmicos fossem discutidos, como aborto, união entre pessoas do mesmo sexo, a criminalização da homofobia, a adoção de crianças por casais homossexuais, a inclusão da cirurgia de redesignação sexual no SUS (Sistema Único de Saúde), entre outros. Mesmo que de forma desigual, esse movimento viu muitas de suas pautas serem levadas à discussão pelo governo, especialmente entre os anos de 2003 a 2010 (MACHADO, 2012). 
Contudo, contrário as vitórias já estabelecidas, percebe-se atualmente no Brasil o surgimento e a força de movimentos conservadores e retrógrados em relação a essas minorias. O governo, por exemplo, cedeu a pressões populares conservadoristas e vetou a distribuição do "kit anti-homofobia" nas escolas. Ademais, uma observação muito importante, é que "o avanço das políticas de direitos humanos em atendimento às demandas dos movimentos feministas e gays" (MACHADO, 2012) está correspondido ao grande aumento no número de religiosos na política e no poder legislativo, visando principalmente, interromper, atrasar ou vetar importantes demandas das comunidades gays, lésbicas, bissexuais, travestis e transexuais (MACHADO, 2012; GONZAGA et al., 2019). Diante destes acontecimentos, evidencia-se ainda mais a necessidade de discutir sobre essas temáticas, inclusive no meio organizacional, ponto focal deste trabalho, a fim de não permitir com que a atual conjuntura política conservadora do nosso país diminua as questões já conquistadas por esse movimento importante da sociedade (SENGER, 2014; BENÍTEZ et al., 2018).

\section{A diversidade sexual e de gênero nas organizações}

No decorrer dos últimos anos, os temas relacionados à diversidade têm conquistado espaço no mundo corporativo, entre eles, a diversidade sexual e de gênero. Em meados da segunda década do século XXI já é possível perceber que mulheres, negros, homossexuais e outras minorias começam a ser objeto de esforço das organizações, que visam promover a inclusão e a igualdade entre as pessoas, mesmo que muitas vezes essas ações sejam promovidas somente de forma discursiva, a fim de passar a imagem de uma organização preocupada com a diversidade (FREITAS et al., 2012; SOARES et al., 2018; ETHOS, 2013). Porém, mesmo com tais medidas adotadas por algumas organizações, ainda é perceptível a grande dificuldade enfrentada pelas pessoas LGBTQ+ não somente na inserção no mercado de trabalho, mas também e sobretudo na sua permanência (YILMAZ et al., 2016).

A Consultoria Santo Caos (2015) realizou uma pesquisa com 230 pessoas LGBTQ+, sendo possível verificar que 1 a cada 4 entrevistados acreditam que a orientação sexual tem algum tipo de influência na escolha da carreira e a maior parte deles não vê uma predisposição de pessoas LGTBQ+ em determinadas profissões mais formais ou tradicionais, como engenharias e direito. A Consultoria também destaca que há um fator cultural muito forte que associa, por exemplo, as profissões da área da beleza à feminilidade e por extensão, associa também os homens gays a esse universo, corroborando com a ideia de Zanin et al. (2019) que ressalta que existe há uma separação do que é ou não aceitável dentro dos ambientes organizacionais. (ZANIN et al., 2019).

Na mesma pesquisa também foi possível levantar que 53\% dos entrevistados não declaram sua orientação sexual no trabalho por medo de sofrerem discriminação, demissão ou de terem questionadas as suas habilidades profissionais e $40 \%$ já sofreram discriminação no trabalho, tendo como as principais situações descritas: piadas sem consentimento, por parte de colegas e superiores, assédio moral e exposição por colegas, seguidas de pedido de demissão. Por receio, pessoas acabam inventando uma vida "paralela" e criando maneiras de não revelar sua orientação sexual para os colegas (SANTO CAOS, 2015). 
De acordo com Souza et al. (2013), às organizações reproduzem os princípios e regras da sociedade em que estão inseridas, sendo assim, ou seja, uma organização que faz parte de uma sociedade em que o padrão considerado normal é o heteronormativo, irá reproduzir os preconceitos e discriminações oriundos dessa sociedade. Sendo assim, conforme ressaltam os autores, para que haja empresas verdadeiramente inclusivas, faz-se necessário uma sociedade inclusiva.

Atualmente, os movimentos sociais pressionam o governo e as instituições privadas no tocante às ações afirmativas voltadas para as pessoas gays, lésbicas, bissexuais, travestis e transexuais e as empresas dão os primeiros passos rumo a um ambiente corporativo mais diversos e igualitário (FARINHA, 2018; FARINA, 2014; SOARES et al., 2018). No ano de 2013 foi criado o Fórum de empresas e direitos LGBTs, o qual discute sobre as especificidades das políticas relacionadas a essas minorias no mundo corporativo (SALES, 2015; SALES, 2017), nos quais empresas brasileiras e multinacionais são signatárias, entre elas grandes marcas reconhecidas pela população brasileira: Coca-Cola Brasil, AVON, VIVO, Itaú, entre outras.

Nesse Fórum, algumas empresas se envolvem de maneira mais próxima, entretanto, “outras, enviam seus representantes apenas para assistir ao evento, acompanhar os debates, fazer contatos e benchmarking" (SALES, 2017), o que corrobora com a ideia de que muitas vezes as ações promovidas pelas organizações são somente de forma discursiva, a fim de passar a imagem de uma empresa preocupada com a diversidade, mas sem promover de fato o apoio e a promoção à diversidade (FREITAS et al., 2012; SOARES et al., 2018; ETHOS, 2013).

Esses dados reforçam a importância da criação de políticas de inclusão e diversidade nas empresas (SOARES et al., 2018). Logo, diante de tantas violações a existência das minorias LGBTQ+ nos ambientes organizacionais, é perceptível que se faz necessário de forma urgente a criação e implementação de políticas afirmativas que visem reequilibrar a igualdade frente aos evidentes prejuízos de um grupo em relação a outro no acesso e permanência ao mercado de trabalho (GOMES, 2008; ZANIN et al., 2019).

\section{METODOLOGIA}

No que se refere aos procedimentos metodológicos adotados no presente trabalho, este estudo caracteriza-se como uma pesquisa bibliométrica, que se destina a quantificar, identificar, analisar e descrever uma série de padrões referentes a produção de pesquisa científica de determinado tema ou assunto em questão (ARAÚJO, 2006). Neste caso, a partir do levantamento de artigos científicos sobre a temática da diversidade organizacional, publicados entre os anos de 2006 a julho de 2020 nos principais eventos da ANPAD: Encontro da Associação Nacional dos Programas de Pós-graduação em Administração (EnANPAD), Encontro de Gestão de Pessoas e Relações de Trabalho (EnGPR) e Encontro de Estudos Organizacionais (EnEO).

Em um primeiro momento, foram selecionados os artigos que possuíam no título a palavra 'gay', 'lésbica', 'homossexual' e 'Igbt'. No segundo estágio, os trabalhos localizados foram lidos, a fim de verificar se realmente tratavam sobre a temática da diversidade sexual e de gênero nas organizações. Sequencialmente, apresentam-se os resultados obtidos neste estudo. 


\section{RESULTADOS E DISCUSSÃO}

Os resultados do estudo permitiram verificar que foram publicados um total de 40 trabalhos com a temática diversidade sexual e de gênero, a partir da busca pelas palavras-chave 'gay', 'lésbica', 'homossexual' e 'LGBT' entre os anos de 2006 a julho 2020, realizada nos eventos da Associação Nacional dos Programas de Pós-Graduação em Administração (ANPAD).

Tal fato, possibilita verificar que mesmo sendo reconhecida a atual relevância sobre a temática e sua ascensão nas pesquisas, ainda existe um número reduzido de trabalhos publicados no contexto nacional. Dentre esses, 31 trabalhos apresentam o foco organizacional no título ou resumo dos estudos. A fim de elucidar tais resultados, no Quadro 1 apresenta-se um esquema em relação a caracterização geral dos referidos trabalhos.

Quadro 1: Caracterização geral dos trabalhos sobre Diversidade nas Organizações.

\begin{tabular}{|c|c|c|c|c|}
\hline Número & Ano & Evento & Título & Autor(es) \\
\hline 1 & 2006 & EnEO & Diversidade e Identidade Gay nas Organizações & $\begin{array}{l}\text { Marcus Vinicius Soares Siqueira; } \\
\text { Amanda Zauli-Fellows }\end{array}$ \\
\hline 2 & 2006 & EnANPAD & $\begin{array}{l}\text { Gays no Ambiente de Trabalho: uma Agenda de } \\
\text { Pesquisa }\end{array}$ & $\begin{array}{l}\text { Marcus Vinicius Soares Siqueira; Renata } \\
\text { Costa Ferreira; Amanda Zauli-Fellows }\end{array}$ \\
\hline 3 & 2007 & EnANPAD & $\begin{array}{l}\text { Estratégia de Sobrevivência dos Gays no Ambiente } \\
\text { de Trabalho }\end{array}$ & Helio Arthur Reis Irigaray \\
\hline 4 & 2007 & EnANPAD & $\begin{array}{l}\text { O Gay no Ambiente de Trabalho: Análise dos } \\
\text { Efeitos de ser Gay nas Organizações } \\
\text { Contemporâneas }\end{array}$ & $\begin{array}{l}\text { Renata Costa Ferreira; Marcus Vinicius } \\
\text { Soares Siqueira }\end{array}$ \\
\hline 5 & 2008 & EnANPAD & $\begin{array}{l}\text { A Inserção da 'Diversidade' Homossexual em uma } \\
\text { Livraria de Shopping Center: um Estudo Crítico }\end{array}$ & $\begin{array}{l}\text { Cláudia Sirangelo Eccel; Maria Tereza } \\
\text { Flores-Pereira }\end{array}$ \\
\hline 6 & 2009 & EnANPAD & $\begin{array}{l}\text { A ficção das Políticas de Diversidade nas } \\
\text { Organizações: as relações de trabalho comentadas } \\
\text { por trabalhadores gays }\end{array}$ & Ana Paula Rodrigues Diniz; Gislaine Gandra \\
\hline 7 & 2009 & EnGPR & $\begin{array}{l}\text { Gays e Relações de Trabalho: Análise sob a Ótica da } \\
\text { Queer Theory }\end{array}$ & $\begin{array}{l}\text { Helio Arthur Reis Irigaray; Maria Ester de } \\
\text { Freitas }\end{array}$ \\
\hline 8 & 2009 & EnANPAD & $\begin{array}{l}\text { Sexualidade nas Organizações Brasileiras: Estudos } \\
\text { sobre Lésbicas no Ambiente de Trabalho }\end{array}$ & $\begin{array}{l}\text { Hélio Arthur Reis Irigaray; Maria Ester de } \\
\text { Freitas }\end{array}$ \\
\hline 9 & 2009 & EnANPAD & $\begin{array}{l}\text { Violência Simbólica e Homossexualidade: um } \\
\text { Estudo em Capitais Brasileiras }\end{array}$ & $\begin{array}{l}\text { Renata de Almeida Bicalho; Ana Paula } \\
\text { Rodrigues Diniz }\end{array}$ \\
\hline 10 & 2010 & EnANPAD & $\begin{array}{l}\text { As Categorias Identitárias que (Re)Produzem } \\
\text { Discriminações: Estudo da Discriminação exercida } \\
\text { por Gays }\end{array}$ & $\begin{array}{l}\text { Eloisio Moulin de Souza; Severino Joaquim } \\
\text { Nunes Pereira }\end{array}$ \\
\hline 11 & 2010 & EnANPAD & $\begin{array}{l}\text { Reflexões sobre o Indivíduo desejante e o } \\
\text { sofrimento no trabalho: o assédio moral, a } \\
\text { violência simbólica, e o movimento homossexual }\end{array}$ & $\begin{array}{l}\text { Alexandre de Pádua Carrieri, Ana Rosa } \\
\text { Camillo Aguiar; Ana Paula Rodrigues Diniz }\end{array}$ \\
\hline 12 & 2014 & EnANPAD & $\begin{array}{l}\text { Desenhando a Vivência: um estudo sobre } \\
\text { Sexualidade, Tabu e Trabalho de Homens Gays }\end{array}$ & $\begin{array}{l}\text { Henrique Luiz Caproni Neto; Paula } \\
\text { Fernandes Furbino Bretas; Luiz Alex Silva } \\
\text { Saraiva; Alexsandra Nascimento da Silva } \\
\end{array}$ \\
\hline 13 & 2014 & EnANPAD & $\begin{array}{l}\text { Contradições entre Essência e Aparência nos } \\
\text { Processos de Empoderamento de Gays em } \\
\text { Organizações de Trabalho }\end{array}$ & Alex Fernandes Magalhães \\
\hline 14 & 2015 & EnANPAD & $\begin{array}{l}\text { Constituição e Administração da Identidade de } \\
\text { Gênero Homossexual Masculino no Trabalho e sua } \\
\text { Articulação com o Consumo }\end{array}$ & $\begin{array}{l}\text { Marcia Pereira Santos; Ivaneide Nunes } \\
\text { Paulino Grizente }\end{array}$ \\
\hline 15 & 2016 & EnEO & $\begin{array}{l}\text { O Problema não É Ser Gay, É ser Feminino: O Gay } \\
\text { Afeminado e as Organizações }\end{array}$ & $\begin{array}{l}\text { Renan Gomes de Moura; Rejane Prevolt } \\
\text { Nascimento; Denise Franca Barros }\end{array}$ \\
\hline 16 & 2016 & EnANPAD & $\begin{array}{l}\text { O Complexo de Gulliver e o Silêncio dos } \\
\text { Empregados Gays nas Organizações Brasileiras }\end{array}$ & $\begin{array}{l}\text { Breno Machado Cola; Marcia Juliana } \\
\text { D'angelo }\end{array}$ \\
\hline 17 & 2016 & EnANPAD & $\begin{array}{l}\text { Vozes não ouvidas? Compreendendo como } \\
\text { Empregados Gays Coconstroem um Clima de } \\
\text { Voz/Silêncio nas Organizações }\end{array}$ & $\begin{array}{l}\text { Bruno Felix Von Borell de Araujo; Alciares } \\
\text { Mello dos Santos }\end{array}$ \\
\hline 18 & 2016 & EnANPAD & $\begin{array}{l}\text { As Decisões de Carreira Dual de Gays: a Inter- } \\
\text { Relação entre Carreira, Trabalho e Família }\end{array}$ & Fernanda Cássia de Castro; Tania Casado \\
\hline
\end{tabular}




\begin{tabular}{|c|c|c|c|c|}
\hline 19 & 2017 & EnANPAD & $\begin{array}{l}\text { A Relação Entre a Discriminação Percebida e a } \\
\text { Satisfação no Trabalho: um Estudo com } \\
\text { Funcionários LGBT }\end{array}$ & Giacomina Possatti Lepaus \\
\hline 20 & 2017 & EnANPAD & $\begin{array}{l}\text { Gays e Lésbicas: Enfrentando as Barreiras Visíveis e } \\
\text { Invisíveis no Trabalho }\end{array}$ & $\begin{array}{l}\text { Carolina Maria Mota dos Santos; Mariana } \\
\text { de Lima Caiero; Antonio Carvalho Neto; } \\
\text { Fernanda Versiani de Rezende; Marina } \\
\text { Kraiser; Andrea Leite Rodrigues }\end{array}$ \\
\hline 21 & 2017 & EnANPAD & $\begin{array}{l}\text { Divulgação da Identidade Gay: Um Modelo sobre a } \\
\text { Interação Entre Estrutura e Agência }\end{array}$ & Alciares Mello dos Santos \\
\hline 22 & 2017 & EnANPAD & $\begin{array}{l}\text { O Self no Armário: compreendendo o silêncio de } \\
\text { gays e de lésbicas no ambiente de trabalho }\end{array}$ & $\begin{array}{l}\text { Rômulo Gomes; Bruno Felix Von Borell de } \\
\text { Araujo }\end{array}$ \\
\hline 23 & 2018 & EnANPAD & $\begin{array}{l}\text { Diversidade para quê? Motivações para o } \\
\text { Desenvolvimento de Práticas Voltadas à Inclusão } \\
\text { da População LGBT em Organizações } \\
\text { Multinacionais que Atuam no Brasil }\end{array}$ & Ricardo Gonçalves de Sales \\
\hline 24 & 2018 & EnANPAD & $\begin{array}{l}\text { O Gay Afeminado Frente a Masculinidade } \\
\text { Hegemônica no Contexto Organizacional: Um } \\
\text { Estudo com Homossexuais Masculinos }\end{array}$ & $\begin{array}{l}\text { Renan Gomes de Moura; Rejane Prevont } \\
\text { Nascimento; }\end{array}$ \\
\hline 25 & 2019 & EnEO & $\begin{array}{l}\text { A Masculinidade Tóxica e Seus Impactos na Vida de } \\
\text { Gays Dentro das Organizações }\end{array}$ & Renan Gomes de Moura \\
\hline 26 & 2019 & EnEO & $\begin{array}{l}\text { A História de Vida de Renato: Reflexões Sobre } \\
\text { Homofobia, discriminação, Assédio e Violência } \\
\text { Contra Gays no Brasil }\end{array}$ & Lorenço Rodrigues; Fernanda Tarabal Lopes \\
\hline 27 & 2019 & EnEO & $\begin{array}{l}\text { Diversidade Sexual nas Organizações? A distância } \\
\text { entre teoria e realidade na visão de trabalhadores } \\
\text { gays de uma empresa estatal brasileira }\end{array}$ & $\begin{array}{l}\text { Neimar Filipon; Ana Christina Celano } \\
\text { Teixeira; Lucia Barbosa de Oliveira }\end{array}$ \\
\hline 28 & 2019 & EnEO & $\begin{array}{l}\text { A Ortopedia Cristã: Os dispositivos discursivos na } \\
\text { construção de corpos gays masculinos em } \\
\text { organizações religiosas cristãs }\end{array}$ & $\begin{array}{l}\text { Luiz Eduardo Pereira Batista; André } \\
\text { Rodrigues Silveira; Adriana Vinholi } \\
\text { Rampazo }\end{array}$ \\
\hline 29 & 2019 & EnEO & $\begin{array}{l}\text { A Barreira entre os Gays e o Mercado de Trabalho: } \\
\text { um Estudo Sobre a Discriminação de Homens Gays } \\
\text { no Setor de Telecomunicações }\end{array}$ & $\begin{array}{l}\text { Diogo Barros Azevedo; Luiz Eduardo Pereira } \\
\text { Batista; Adriana Vinholi Rampazo; Luiz } \\
\text { Bruno de Bom da Silveira }\end{array}$ \\
\hline 30 & 2019 & EnANPAD & $\begin{array}{l}\text { 'Eu Tento Não Me Esconder, Nunca': As Estratégias } \\
\text { Utilizadas Pelos Profissionais Gays E Lésbicas Para } \\
\text { Minimizar Os Estigmas Sexuais Nos Espaços de } \\
\text { Trabalho }\end{array}$ & $\begin{array}{l}\text { Fernanda Versiani de Rezende; Camila } \\
\text { Veloso Antunes; } \quad \text { Antonio Carvalho } \\
\text { Neto; Carolina Maria Mota Santos }\end{array}$ \\
\hline 31 & 2020 & EnGPR & $\begin{array}{l}\text { Inclusão e Diversidade no mercado de trabalho sob } \\
\text { a perspectiva de estudantes LGBT+ da Escola de } \\
\text { Administração da Universidade Federal da Bahia }\end{array}$ & $\begin{array}{l}\text { Luiza Sampaio Moreira; Daniela Campos } \\
\text { Bahia Moscon; }\end{array}$ \\
\hline
\end{tabular}

Conforme é possível observar no Quadro 1, grande parte dos trabalhos publicados nos eventos da ANPAD tratam sobre as temáticas no ambiente de trabalho, com total de 31 trabalhos publicados. Outro tema relevante foi referente aos preconceitos, discriminações e violências sofridas por essas minorias no ambiente de trabalho. Também foi possível verificar a existência de artigos relacionados à diversidade nas organizações. Para complementar tal análise, na Tabela 1 foi realizada a apuração do número de publicações sobre a temática por ano, nos últimos 15 anos.

Tabela 1: Quantidade de pesquisas por ano.

\begin{tabular}{|l|l|}
\hline Ano & Número de publicações \\
\hline 2006 & 02 \\
\hline 2007 & 02 \\
\hline 2008 & 01 \\
\hline 2009 & 04 \\
\hline 2010 & 02 \\
\hline 2014 & 02 \\
\hline 2015 & 01 \\
\hline 2016 & 04 \\
\hline 2017 & 04 \\
\hline 2018 & 02 \\
\hline 2019 & 06 \\
\hline 2020 & 01 \\
\hline
\end{tabular}


Conforme apresentado na Tabela 1, percebe-se um aumento significativo no número de publicações sobre o referido tema nos eventos da ANPAD, especialmente nos anos de 2016 e 2019. Além disso, optou-se por realizar também uma análise por meio de uma nuvem de palavras elaborada no site WordArt, a partir dos títulos dos trabalhos publicados nos eventos da Anpad entre os anos de 2006 a julho de 2020 sobre a temática, à qual é possível visualizar na Figura 1.

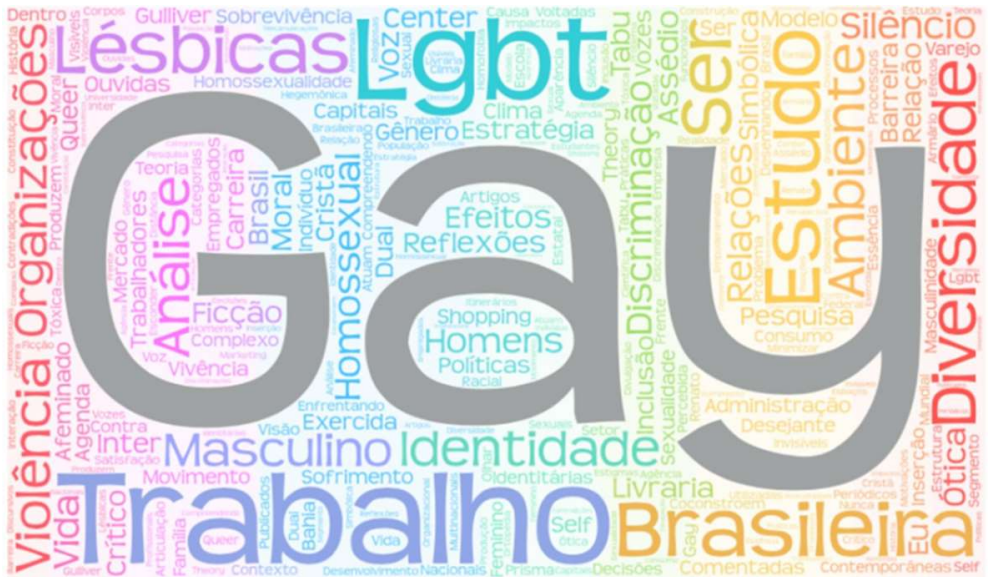

Figura 1: Nuvem de palavras dos títulos dos trabalhos da ANPAD sobre a temática.

A partir da nuvem de palavras exposta na Figura 1 é possível verificar a grande ocorrência das palavras gay, lésbicas, LGBT, trabalho, organizações, diversidade, violência, entre outras como as mais destacadas nos estudos realizados. Diante disso, pode-se compreender que a utilização de tais expressões delimita os contextos das pesquisas realizadas, dando ênfase aos estudos que abordam as temáticas gays, lésbicas, LGBT, trabalho e organizações. Tal fato, pode ser considerado um importante avanço nas discussões sobre a diversidade sexual e de gênero, especialmente nas organizações brasileiras, já que é perceptível a necessidade de buscar reflexões acerca das problemáticas enfrentadas por essas pessoas no mercado de trabalho, tornando-se ainda imprescindível dar luz sobre as relações existentes dentro do ambiente organizacional e refletir sobre a complexidade envolta nos processos de construção da identidade desses sujeitos (BISCALCHIM et al., 2016).

Ao averiguar o conteúdo dos trabalhos, foi possível identificar que as pesquisas que tratam sobre as vivências das pessoas LGBTQ+ dentro dos ambientes organizacionais têm alguns pontos em comum, entre eles a dificuldade de pessoas gays assumirem sua sexualidade no trabalho e o medo de agirem da forma como agem nas suas vidas particulares, com trejeitos, vozes, andar e se comunicar, tal medo justifica-se pelo fato de que essas pessoas podem sofrer preconceito por parte de seus colegas e superiores se agirem de tal maneira. Já os artigos que tratam sobre preconceito, discriminação e violência destacam que as minorias sexuais e de gênero sofrem preconceito dentro dos seus ambientes de trabalho, como piadas de mal gosto, por exemplo, o que confirma o exposto por Donelly (2003) de que as minorias sexuais e de gênero são vítimas de discriminação e preconceito unicamente por serem e agirem da forma como agem.

Por fim, os artigos com a temática da diversidade sexual nas organizações tratam o assunto de forma mais ampla e abrangente, em um contexto no qual a diversidade passou a ser uma característica dos trabalhadores das organizações, sendo que esses trabalhos visam analisar a cultura e a identidade gay a fim 
de que haja uma melhora nas relações de trabalho entre colaboradores e empresas.

\section{CONCLUSÕES}

Com base nos resultados do presente estudo, foi possível averiguar que as pesquisas realizadas trazem importantes contribuições para o meio científico e acadêmico acerca da temática da diversidade sexual e de gênero nas organizações, envolvendo especialmente indivíduos que se enquadram nas palavraschave pesquisadas. Também foi possível verificar as significativas colaborações para a área de Gestão Pessoas, com o aumento no número de pesquisas sobre a temática, aqui exposta, no campo organizacional.

Ainda, dentro das percepções, identificou-se que a palavra-chave mais utilizada até 2016 foi o termo 'gay', orientação sexual designada para homens que têm relação com outros homens. Compreende-se que a expressão em geral tenha sido utilizada como uma forma de especificar a direção das pesquisas, de maneira menos ampla, e dando enfoque ao cenário das organizações para os homens gays. Posteriormente, a partir de 2016, foram surgindo pesquisas mais amplas, que utilizam o termo 'LGBT', e assim possibilitam maior inclusão e demais cenários a serem explorados nas realizações dos estudos.

Neste contexto, é notório o crescimento de publicações dentro da plataforma da Associação Nacional de Pós-graduação e Pesquisa em Administração (ANPAD) sobre a temática, o que demonstra o interesse por parte dos pesquisadores em compreender melhor de que forma a inclusão está acontecendo dentro das empresas. Ademais, é importante ressaltar que pesquisas sobre esse assunto são significativas para além de qualificar tais fatos, possibilitando quantificá-los e retratar na prática de que forma ocorre a inclusão de LGBTs no mercado de trabalho.

Como limitação do estudo e sugestão de continuidade da pesquisa aponta-se a necessidade de se ter um melhor detalhamento e aprofundamento dos achados aqui apresentados. Mesmo assim, espera-se que a realização desta pesquisa contribua para a área acadêmica, instigando novos estudos relacionados ao tema abordado.

\section{REFERÊNCIAS}

ARAGUSUKU, H. A.; LOPES, M. A. S.. Políticas Públicas para LGBT em Mato Grosso: levantamento histórico e perspectivas. Humanidades em contexto: saberes e interpretações. Cuiabá: ICHS, 2014.

ARAÚJO, C. A.. Bibliometria: evolução história e questões atuais. Em Questão, Porto Alegre, v.12, n.1, p.11-32, 2006.

BENITTEZ, M. E. D.; GONÇALES, N. F.. Por dentro do ringue: gênero e sexualidade no embate da inclusão por direitos. Revista Ñanduty, v.6, n.8, 2018.

BISCALCHIM, S. M.; ARAUJO, R. K.. Políticas públicas para ingresso da(o) jovem LGBT no mercado. Curitiba: Universidade Federal do Paraná, 2016.

CARRARA, S.; RAMOS, S.. A Constituição da Problemática da Violência contra Homossexuais: a Articulação entre Ativismo e Academia na Elaboração de Políticas Públicas. PHYSIS: Rev. Saúde Coletiva, Rio de Janeiro, v.16, n.2, p.185-205, 2006.
DEBELUCK, B.; TIMM, N.. Famecos lança estudo sobre conceitos de família: levantamento foi feito pelo Núcleo de Tendências e Pesquisa do Espaço Experiência. Porto Alegre, 2015.

DONELLY, J.. Universal Human Rights in Theory \& practice. 2 ed. Nova lorque: Cornell University, 2003.

ETHOS. Instituto Ethos de Empresas e Responsabilidade Social. O compromisso das empresas com os LGBT direitos humanos. 2013.

FARINA, E.. Empresas desenvolvem ações para banir preconceito sexual: Projetos promovem a inclusão de trabalhadores gays, lésbicas e transexuais no ambiente de trabalho. 2014 
FARINHA, C. A.. Um olhar sobre a inclusão da diversidade sexual nas organizações. Perspectivas em Políticas Públicas, v.10, n.2, p.211-240, 2018.

\section{FREITAS JUNIOR, A. R.. Direito do trabalho e direitos humanos. São Paulo: BH, 2006.}

FREITAS, M. E.; DANTAS, M.. Diversidade sexual e trabalho. São Paulo: Cengage Learning, 2012.

GOMES, F. R.. O direito fundamental ao trabalho: uma miragem discursiva ou uma norma efetiva? In: SARMENTO, D.. Direitos sociais: fundamentos, judicialização e direitos sociais em espécie. Rio de Janeiro: Lumen Juris, 2008.

GONZAGA, T. M. S.; GALLAS, A. K. C.. O Retrocesso no combate da LGBTfobia no Brasil. Filosofia e Educação, v.11, n.2, 2019

HEREK, G. M.. The social context of hate crimes: notes on cultural heteroxism. In: HEREK, G. M.; BERRIL, K. T.. Hate crimes: confronting violence against lesbians and gay men. Newburry: Sage, 1992. p.89-104.

JUNQUEIRA, R. D.. Homofobia: Limites e possibilidades de um conceito em meio a disputas. Revista Bagoas, v.1, n.1, p.1-22, 2007.

MACHADO, M. D. C.. Religião, cultura e política. Religião e Sociedade, v.32, n.2, p.29-56, 2012.

MELLO, L.; BRITO, W.; MAROJA, D.. Políticas públicas para a população LGBT no Brasil: Notas sobre alcances e possibilidades. Cadernos Pagu, v.39, p.403-429, 2012.

NOGUEIRA, G.; COLLING, L.. Homofobia, heterossexismo, heterossexualidade compulsória, heteronormatividade. In: COLLING, A. M.; TEDESCHI, L. A.. Dicionário Crítico de Gênero. Dourados: UFGD, 2015.

ONU. Organização das Nações Unidas. Declaração Universal dos Direitos Humanos. Assembleia Geral das Nações Unidas em Paris. ONU, 1948.

PRADO, M. A.; MACHADO, F. V.. Preconceito contra homossexualidades: ahierarquia da invisibilidade. São Paulo: Cortez, 2008.

SALES, R. G.. Diversidade no trabalho: valores organizacionais e adesão às normas em organizações participantes do Fórum Empresas e Direitos LGBT. In: CONGRESSO INTERNACIONAL COMUNICAÇÃO E CONSUMO, 5. Anais. São Paulo, 2015.

SALES, R. G.. Políticas de respeito à diversidade sexual no ambiente de trabalho: análise das percepções sobre o papel da comunicação em organizações participantes do Fórum de Empresas e Direitos LGBT. Dissertação (Mestrado) Universidade de São Paulo, São Paulo, 2017.

SANTO CAOS. Demitindo preconceitos: Porque as empresas precisam sair do armário. 2015.

SENGER, D.. Homofobia no Brasil: projetos de lei e políticas públicas em defesa dos direitos da população LGBT e o discurso religioso da bancada evangélica. In: CONGRESSO INTERNACIONAL DA FACULDADES EST, 2. Anais. São Leopoldo: EST., 2014.

SOARES, A. P.; SANDER, A.. A diversidade nas organizações e os obstáculos na ascensão profissional de colaboradores LGBT. Revista Metodista de Administração do Sul, v.3, n.4, p.39-77, 2018.

SOUSA, K. J. A.. As diversas manifestações homofóbicas e suas consequências no cotidiano das minorias LGBT. Revista Clóvis Moura de Humanidades, Teresina, v.2, n.1, p.27-44, 2016.

SOUZA, E. M.; PEREIRA, S. J. N.. (Re) Produção do heterossexismo e da heteronormatividade nas relações de trabalho: A discriminação de homossexuais por homossexuais. Revista de Administração Mackenzie, v.14, n.4, p.76-105, 2013.

TUC. Trades Union Congress. The Cost of Being Out at Work LGBT+: workers' experiences of harassment and discrimination. Londres: Trades Union Congress, 2017.

YILMAZ, V.; GÖÇMEN, İ.. Denied citizens of turkey: experiences of discrimination among LGBT individuals in employment, housing and health care. Gender, Work \& Organization, New Jersey, v.23, n.5, p.470-488, 2016.

ZANIN, H. S.; FERREIRA, L. S.; RIBEIRO, L. P.. Ingresso e permanência no trabalho e emprego por sujeitos LGBT+ em Belo Horizonte, Brasil. Rev. Mult. Psic., v.13, n.44, p.460474, 2019.

A CBPC - Companhia Brasileira de Produção Científica (CNPJ: 11.221.422/0001-03) detém os direitos materiais desta publicação. Os direitos referem-se à publicação do trabalho em qualquer parte do mundo, incluindo os direitos às renovações, expansões e disseminações da contribuição, bem como outros direitos subsidiários. Todos os trabalhos publicados eletronicamente poderão posteriormente ser publicados em coletâneas impressas sob coordenação da Sustenere Publishing, da Companhia Brasileira de Produção Científica e seus parceiros autorizados. Os (as) autores (as) preservam os direitos autorais, mas não têm permissão para a publicação da contribuição em outro meio, impresso ou digital, em português ou em tradução. 